\title{
Digital customer experience: the risk of ignoring the non-digital experience
}

\author{
Marcel Weber \\ Founder, 3Cl Customer Co-Creation, Waalwijk, the Netherlands, marcelweber4@gmail.com \\ Christos G. Chatzopoulos \\ Ashcroft Instruments GmbH, Germany, christos.chatzopoulos@ashcroft.com
}

Received (04-OCT-2018); Revised (05-AUG-2019); Accepted (08-AUG-2019)

\begin{abstract}
Digital technology can change the customer journey from a regular customer experience (CX) into a digital CX where touchpoints are supported by digital means. However, a focus on merely digital CX may be risky because $C X$ is dependent on what occurs at touchpoints other than those that are digital. Some experts assert digital experience exerts a small influence on the total customer experience (TCX). In this paper, we discuss whether a strategic focus on digital CX is beneficial or disadvantageous to a company that operates online. In addition, we consider the conditions a company must contemplate in evaluating if digital CX has more impact on TCX. The paper presents a conceptual discussion based on a review of the literature and evidence from practice. Findings from two case studies indicate that emphasis on TCX is more important than focusing only on digital CX, which can lead to counter-productive results for customers and decrease the importance of non-digital CX.
\end{abstract}

Key words: Customer Experience, Digital Customer Experience, Non-Digital Customer Experience, Total Customer Experience

\section{INTRODUCTION}

Customer focus, customer orientation and a perfect $\mathrm{CX}$ are virtues that many companies desire or seek. Customers are no longer regarded as rational deciders with mere interest in functional and financial product properties and benefits. A satisfied customer is not a guarantee for loyalty, additional revenue, or a larger market share. Companies have to consider delivering consistently positive and distinctive CX in order to increase loyalty and customer advocacy. The difficulty, of course, is how to create and manage these unique experiences. To answer this question, some scholars and practitioners have focused their research and publications on the concept of customer experience management (CEM) [1]. However, much of the literature, aside from the conceptual nature, focus on yielding TCX, where the end-to-end customer journey or value chain matters [2].

One of the major developments in business has been the emergence of the Internet as a channel for commerce. The entire selling and buying process, from information search, communication, and selection, to transaction, delivery, and after-sales service, can nowadays be largely conducted across the digital channel [1]. Many mass customization (MC) firms have focused their efforts on optimizing digital production and customization through product configurators and the ordering process [3], in an effort to increase customers' process enjoyment and fulfilment [4]. Similarly, many online product or service providers have made efforts to improve the online experience as a means to increase customer loyalty [5]. The focus of numerous companies, including supporting academic research, has been on the digital use experience [6]. But CX, specifically TCX, is not determined by such actions alone, because an important part of the MC process consists of other activities which are of a more physical nature, i.e., the distribution system that includes packaging, storing and delivering the final product to the customer [7]. Additive manufacturing technology, also known as Industry 4.0, has made it possible to digitalize the distribution process [8], extending the digital contribution in the customer's total experience. Further, TCX is determined by use, operation, maintenance, support, sustaining, phase-out, retiring, recycling and disposal of the product (or service), much of which are still of a largely physical nature.

The question is whether it is harmful to concentrate on digital $\mathrm{CX}$ while neglecting the effect on channels other than digital. In this article, we will discuss if strategic emphasis on the digital experience is beneficial or detrimental to an online operating company, whether for mass customization or otherwise. We begin with a theoretical discourse on the advantages and disadvantages of a focus on digital $\mathrm{CX}$ by introducing several concepts that relate to CEM theory, followed by examination of two case studies of online companies which exemplify our discussion. We will conclude with implications for firms and future research. 


\section{THEORETICAL BACKGROUND AND REFLECTIONS}

\subsection{Customer experience}

Experience is not tacit and concrete, but refers to the qualification of one's subjective, and therefore personal perceptions [9, 10]. Experience can manifest itself in many ways, such as physical, mental, emotional, and even virtual experiences [11]. When referring to the experiences that result from customers' interactions with organizations, we use the term CX. Thus, CX is defined as "... a personal and subjective response that customers have on direct or indirect contact with an organization. The organization tries to evoke several kinds of perceptions to a customer by influencing this CX: emotional, physical, sensorial, rational and relational, where customers and the organization cocreate unique, meaningful experiences in order to achieve a profitable, durable and affective relationship that gives value to all stakeholders" [1].

The role and importance of experience in consumption and use of goods and services was first proposed by Holbrook and Hirschman [12], who introduced CX, advancing contemporary consumer behaviour models that were mainly based on rational behaviour of consumers. Furthering this new perspective, Schmitt advises "to treat consumers as living human beings with experiential needs, rather than as rational price- and attribute-driven information seekers and givers" [13]. Consumers want to experience that their feelings, senses and souls are being "touched" and are in search of authentic and honest treatments by providers [1]. Consumption is no longer a matter for "customers" in the depersonalized sense, but holistic for individuals [13]. According to Pine and Gilmore [14], experiences occur when customers are being involved in such a way that those experiences provide permanent and unforgettable impressions.

Initially, CX was considered a hedonic aspiration of customers $[12,15,16]$, but this way of thinking has changed over time. Nowadays, five types of consumers are observed, based on their different experiential appeals [17]. These groups of consumers are holistic consumers (who are interested in all aspects of experience), hedonistic consumers (who attach importance to sensory and affective dimensions), action-oriented consumers (who focus on physical actions and behaviours), inner-directed consumers (who focus on internal processes which are sensations, emotions and thoughts) and utilitarian consumers (who are low-experiential customers) [17].

\subsection{Customer Experience Management - CEM}

Creating superior $\mathrm{CX}$ seems to be one of the central objectives in today's business environment [18]. Firms, retailers in particular, have embraced the concept of CEM, ensuring a positive experience for customers by focusing on convenience, value and quality, or the best $\mathrm{CX}$ in the markets the firm serves [18]. There is now widespread acceptance that marketing is no longer sufficient to ensure long-term customer loyalty, but that creating a positive $\mathrm{CX}$ leads to high levels of customer satisfaction and is an important step towards durable customer relationships [19].

To manage a customer's experience, the company should understand what $\mathrm{CX}$ actually means. It must recognise that $C X$ is evoked at every point of contact at which the customer interacts with the business, its product, its service, its communication and other utterances made by the organization, including advertising [20]. For instance, retailers have to move from a focus on selling goods and services to enhancing the CX [21].

CEM is proposed as the new way to gain insight on customers' preferences and needs which influence behavior and loyalty [22]. Firms realize that relationships based on experiences will aid in the attraction and retention of customers [14, 18]. CEM represents a business strategy designed to manage $\mathrm{CX}$, one that results in a win-win value exchange between the provider and its customers. Therefore, organizations can undertake actions to manage their customers' experiences [11, 23]. They can implement and guide the so called experience providers, i.e., communication, visual and verbal identity, product presence, social media, etc. [11]. Berry, Carbone and Haeckel [24] suggest that organizations should have an eye for all "clues" that customers can detect in a transaction process. Experience providers and clues have to be managed in detail, and should be used to their fullest potential to create great CX [11]. Attention has to be given to the spatial environment, the influence of other customers, waiting lines and waiting time, sounds, visual expressions, cultural differences, educational background, professional experiences, and even weather conditions [18].

CEM is a new lever to create value for customers, as well as for companies [22, 25, 26]. It is now regarded as a way to distinguish the firm from its competitors and to generate more value for customers, firms and their stakeholders. CEM has become essential to survive in today's competitive environment.

\subsection{Total customer experience}

Marketers of product or service brands need to understand the emotional dynamics involved when a customer selects and decides to continue to use those products or services [27]. Connecting emotionally with customers requires an organization to create a cohesive, authentic and sensory-stimulating TCX that pleases and resonates with consumers, as well as communicates effectively and differentiates the organization from the competition [28]. TCX entails the experience an individual can get from all his contacts and touchpoints with an organization or brand in his life. With technological advances, social and global trends, companies can grow closer to their customers, while customers look for more meaningful experiences so they can shape their own existence [29] and improve or enhance their lives. According to Pine and Gilmore [14], "Experiences are not the final economic offering.... When you customize an experience to make it just right for an individual - providing exactly what he needs right now - you cannot help changing that individual. When 
you customize an experience, you automatically turn it into a transformation" (p. 244) and "once the Experience Economy has run its course in the decades to come, the Transformation Economy will take over" ( $p$. 255). In a society where self-actualization and individual welfare gain a central meaning, firms will have to focus on guiding customers in achieving these states by providing meaningful and memorable experiences that transform people's lives [14]. To facilitate such transformations, companies need to construct platforms where they and their customers jointly create context for giving more sense and meaning to individuals' lives [26]. The dialogue between company and customer is the foundation for the co-creation of personalized value, "engaging people to create valuable experiences together, while enhancing network economics" [30].

\subsection{Customer journey}

The customer journey approach was developed as a method to analyze the experiential world of the consumer [31]. It entails all experiences to which a customer is exposed during his interaction with a firm, from long before any transaction takes place to long after that time. The method depicts all touchpoints the customer has with the organization and other stakeholders during his journey. A touchpoint is a specific moment in time when a customer interacts with a company, or assets of a company; and each one is usually a short period of the customer journey [39].

Touchpoints can be classified as human, product, service, communication, spatial, and electronic interaction [32]. Not all touchpoints are equally significant for a customer [56] and may differ substantially between organizations and processes [1]. Aichner and Gruber [32] identify customer touchpoints and their importance in a B2B setting, finding that those classified as human interaction have the highest importance for customer satisfaction, whereas electronic or digital interactions were regarded as significantly less important. Some touchpoints are considered "moments of truth", crucial to and of high impact in creating a meaningful and intended CX [33]. In managing moments of truth, organizations should consider the peak-end rule [34-36], where experiences are evaluated at the peak and end of an interaction, not on what happens in between or at the beginning of the customer journey. A peak or end experience can be either positive or negative, determining the strength and direction of the total experience. Beginning and in between touchpoint experiences are not really forgotten, but left out of the consumer's evaluation of his total interface [37]. How the consumer judges his experience during the customer journey depends on his expectations of what is to come from the firm, and the interactions the customer has before, during and after the journey. In delivering meaningful experiences, firms will benefit from applying the customer journey method and taking the peak-end rule into consideration [38-41].

\section{REFLECTIONS, RESEARCH AIM AND METHOD}

\subsection{Omnichannel or digital?}

The customer journey approach has recently become a popular device to analyse the TCX creation process through different company-offered touchpoints [42]. The importance of this approach and CEM are closely related to the current nature of the marketplace, where technology is assisted, and service encounters have increased the number of delivery channels and touchpoints [1].

Companies may employ various avenues to reach and interact with customers who use multiple channels along their customer journey [18]. However, evaluating the degree to which each channel contributes to the company's success and the ways in which those channels influence one another remains challenging $[39,41]$. In terms of changing service delivery in multichannel systems and the development of new communications/sales channels, the key element of $\mathrm{CX}$ becomes the ability of the company to manage and seek synergies among multiple touchpoints. Technological applications play an important role and consist of digital customization tools such as intelligence query platforms, options evaluation tools, configurators, concurrent and co-design platforms, and others [39]. The increased deployment of new technologies such as smart mobile devices and social networks, and the growing importance of in-store hightech solutions, create new opportunities and challenges for companies. As the line between online and physical channels is blurred, a new approach to channel integration is emerging, the omnichannel, which aims to deliver a seamless customer experience across any and all channels.

Customers are now interacting with companies through a plethora of providers in the value chain and the many resulting potential touchpoints available through the network. In this evolving marketplace, CX and customer behaviour are viewed as two of the most important research issues for scholars and operating challenges for practitioners [42].

Although some companies may choose a single channel strategy, many more are developing marketing strategies based on multiple channels. Studies [43] show that omnichannel strategies enhance the portfolio of service outputs provided to the customer, thus enhancing customer satisfaction and, ultimately, customer loyalty.

Implementing an online channel strategy is challenging because managers must consider covering an extended period, influencing multiple customer touchpoints, implications for face-to-face channels, and functional results. Firms need to have a clear scope and express an achievable development plan for building dynamic capabilities [44]. With many organizations today operating in multichannel or omnichannel environments, channel strategy should be aimed to ensure that a perfect or outstanding $C X$ is created both within and across channels [45]. Using different providers in a firm's value chain, customers want a 
perfect and consistent shopping experience, and a superior customer value. This requires total integration of all aspects of the supply chain and integration of the activities in the different channels [40]. The main benefit and main challenge of the new omnichannel environment is to create immediate access throughout all channels, not only to gain insight into new customer experience-driven behaviour patterns, but also to deliver corresponding experiences [43]. An omnichannel approach not only offers additional opportunities to push products and services, but also helps turn its challenges into opportunities to connect with customers [46] on several fronts, including through social media [44].

An omnichannel strategy should seek to ensure that an outstanding and consistent experience is created both within and across channels [45]. This requires a total integration of all aspects of the supply chain and all activities in the different channels which influence the multiple customer touchpoints during the customer journey. Research shows that firms with well-integrated channels are more successful than single channel or multichannel companies, or poorly-integrated channels [47]. Companies need to take a holistic, integrated approach to create memorable experiences where multidimensional value can be delivered through multiple and sequential stages of experience [48], namely through the customer journey.

Mass customization is a route up the progression of economic value, where it is not about being everything to everybody, but rather producing only and exactly what individual customers want, when they want it [49]. To increase the value for the customer, companies should rethink how they want their customers to experience doing business with them, not focusing solely on what tasks employees do, but also considering how those tasks are performed [50]. Next, whatever the genre of output, many companies wisely leverage digital technology in order to better fuse the physical with the digital channel [40, 50]. More and more people are bringing their technological devices iPods, iPhones, iPads and so on - with them wherever they go, diverting their time, attention and money with always just a glance and a warm glowing trance away from remaining just with the experience. This does not imply that companies should abandon the physical and 'real' channel, for it will now and forevermore provide the richest of experiences; but with increasing migration to digital, the need is to integrate both realms to create new, novel experiences which were never envisioned before [51]. In some cases, this may require greater integration of the digital into the physical; in other cases, it may mean removing digital devices intrusive to the face-to-face experience [40].

A focus on digital CX may seem myopic because it has been demonstrated that indirect experiences in apps play an important role in the holistic service experience. Compared with direct experiences, indirect experiences do not require the actual use of apps or direct contact with the user [52]. Managers are encouraged to not restrict use experiences only to this direct practise. Indirect use experiences enable managers to gain deep insights into the everyday use experiences of current and potential customers [1].

With the rise of Industry 4.0 activities, where distribution is also digitalized [8], one may tend to let the digital experience prevail over the non-digital experience. However, so far our analysis indicates that TCX is also determined by the use, operation, maintenance, support, sustaining, phase-out, retiring, recycling and disposal of a product [40]. Therefore, companies have to optimize the whole CX by focusing on both digital and physical channels, i.e., the multichannel environment, or even more effective, provision of seamless experiences across all channels known as the omnichannel approach.

\subsection{Research aim and method}

The extant literature seems to indicate that is not wise for a company to focus only on one channel even if the complete offering is in the digital channel, because CEM must be aimed to influence TCX. To investigate this, we present two practitioner case studies in the Dutch region. Both describe online webshops, which can be compared to Amazon in that they do not produce the products themselves but deliver third party goods they procure. The data for the two case studies were acquired through project(s) conducted by one of the authors in his capacity as a CX consultant.

For both cases, three to four managers participated in open interviews. Where possible, the managers' reporting was substantiated with data. The difference in data collection for both case studies was that findings for case.com were enriched through qualitative interviews with a sample of the company's customers due to detected satisfaction and loyalty issues.

In the following section, we begin each case describing the company in general, then present the context of its digital experience. We conclude both case descriptions with our observations regarding the advantage or disadvantage of each firm's focus on digital CX.

\section{RESULTS}

\section{1 case.com}

Case.com is a webshop located in the Netherlands and Belgium. The company was founded in 1999 by a German media group with affiliated branches in Germany, the Netherlands, Sweden, Italy and China. The Dutch company survived the Internet bubble and was sold in 2002 as a result of a change in the company's strategy. It made its first profit in 2003. In 2012, a well-known Dutch retail group acquired case.com for 350 million euros. Since its beginning, the company has won several online retail awards. Employing over 1,000 people, case.com began operating its own distribution centre in 2017. That same year, the firm generated revenues of $€ 1.6$ billion. Case.com is the largest online retailer in the Netherlands.

Like Amazon, Case.com started as an online bookstore, expanding its assortment throughout the years with video, audio (CD and DVD), games, gradually becoming an all-product retailer of new and used goods. 


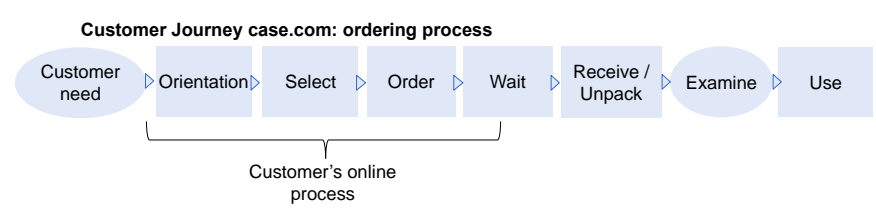

Figure 1. Customer journey of case.com

Initially, the online process consisted of a search engine, product selector with recommendations from other users, an ordering module, and a transaction module with three payment interfaces (iDeal, credit card, and a case.com credit facility). The ordering process is quite simple (see Figure 1): a potential customer can search an online catalogue for the product he seeks, select it by placing it in a cart, pay for the item, provide a shipping address, exit the ordering process, and await delivery. About eight years ago, customers gained the ability to create an online account where they provide profile details such as address, credit card information, (most) wanted list, and can access their order and payment histories, and more.

Case.com invested heavily in improving and aligning its online process throughout the years. Such enhancements included a track-and-trace feature for consumers which displayed the date and time the order was received, sent to the distribution centre, picked and prepared for shipment, so customers could get a feeling of being in control. Distribution was outsourced to the Dutch postal services on whom case.com relied and totally trusted, neither controlling nor monitoring that entity's operations.

To increase online traffic and orders, case.com incorporated a 30-day, hassle-free return policy for customers who were not satisfied with products or their quality. Buyers can return the product free of postal charges in the box they received the delivery. Case.com added product return confirmation to the online process. feature that allowed customers to check the status of order shipments to and receipt by the post office, as well as when delivery could be expected in a four-hour window. The return of defective products was required to be reported online with reference to the order number and date. In addition, customers had to repack returns in their original delivery boxes, deliver them back to postal services locations where they would be provided with a receipt confirming the return. One or two days later, the customer receives a confirmation email indicating that the returned item has been received by case.com's distribution centre. At this time, payment is reimbursed. Customers also have the option of phoning a case.com call centre to report a complaint, malfunction, return, or request assistance with ordering, payment, and other inquiries. However, case.com refrains from handling buyers' calls by using voice response units and redirecting callers to its online $F A Q$.

Upon completing a transaction, whether online or by telephone, the customer is prompted with two questions, one about satisfaction, and the other posing the "ultimate question" [54] enquiry about the intentions of the customer to recommend case.com to others, an indicator of his loyalty. Both customer satisfaction and the Net Promoter Score (NPS) [54] are monitored and reported monthly and yearly.

Despite these online efforts, achievements and awards, customer satisfaction ratings did not rise over time. Case.com believed its typical score of 8 or higher (on a scale of 1 to 10) indicated customers seemed to be very pleased with the online process, thus rendering a good digital experience. However, since 2016 customer satisfaction scores have remained flat, while customer loyalty (NPS) has declined (see Figure 2). It appeared likely that new customers accounted for the high turnover than did existing customers.

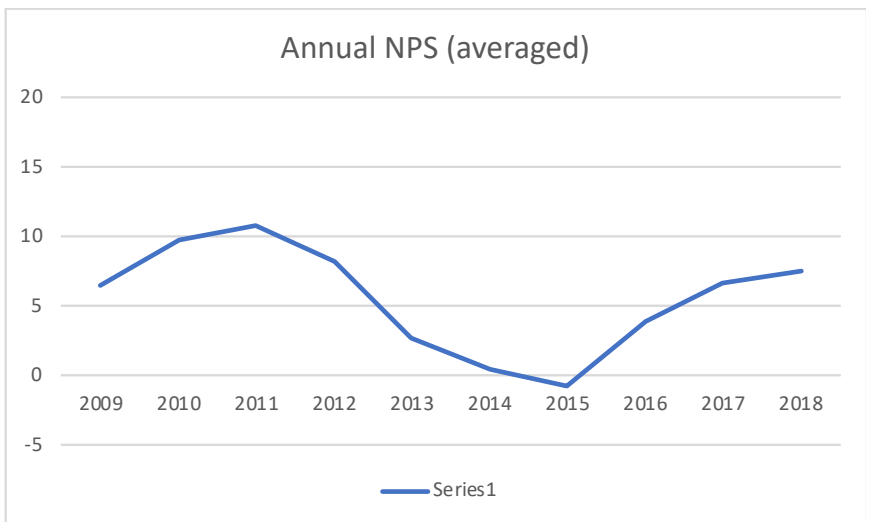

Figure 2. Average Annual Net Promoter Score 2009-2018

Further, data showed that customers' calls to the contact centre had intensified over the same period of time. Investigation of the data indicated these calls were largely about the delivery or return process, even though these processes were digitalized.

Case.com's management were surprised by these results since the company had invested heavily in the digital process. They decided to investigate the problem in depth, requesting assistance from a research agency which specialized in CX where one of this paper's authors is employed. The agency conducted a qualitative study of 16 existing and former case.com customers. Feedback from these consumers revealed they felt well supported online during delivery or product return. Nevertheless, they proceeded to call the contact centre to reassure themselves that they were conducting the required actions correctly. However, when customers called with questions about delivery, case.com representatives could not address the enquiries because the company outsourced its distribution. Delivery time was set by the postal services in 4-hour windows because the organization was unable to predict accurate, specific delivery times as a result of the enormous increase in e-commerce and the dense and heavy traffic in the Netherlands. Therefore, customers had to sacrifice half or a whole day off from work to take delivery of their orders or impose on friendly neighbours to receive their packages for them. In addition to these inconveniences of the delivery process, undelivered packages had to be returned to the post office. Subsequently, the customer receives a note that the package cannot be delivered and he must pick it up within six days. If the customer is unable to 
retrieve it or fails to comply with the pickup timeframe, the post office returns the package to case.com. Consumer frustration with case.com's procedures severely reduced the advantage of buying online instead of in a store: The post office is not nearby, has set opening hours and requires identification in order for a customer to pick up his package. This entire process had a negative impact on case.com's TCX.

Similarly, the return experience was not as hassle-free as assumed by case.com. In their eagerness for the newly received product, customers typically damage the shipping boxes or throw them away before discovering the inadequacy of the items they ordered. Reusing the original container for the return becomes impossible, so the customer grabs the telephone to call case.com in search of alternatives. Another issue encountered during the company's return process was delayed opening or use of orders by customers. Many people leave boxes unopened and unattended because their orders are gifts, or they have no need to use the products immediately. Therefore, several days pass after delivery before one realizes the item ordered is incorrect, defective, no longer needed, or not operating properly. Subsequently, customers worry about still having enough time to return their orders and, again, call case.com about this concern. For the customer, contacting the call centre is a perfectly appropriate tactic. Further, returning an unwanted or defective product requires even further effort by the customer. $\mathrm{He}$ has to physically go to the post office where he experiences the same problems he encountered when he had to do the same to retrieve a package that could not be delivered due to his absence at the initial delivery attempt. Finally, the reimbursement process and timing generate angst for customers since they must wait to be reimbursed when their returned goods have been received by case.com. The burdensome return method induces such resistance from customers that they call case.com hoping to arrange better return deals. As mentioned, when customers are discouraged from making these calls, such creates a sense of frustration in the $\mathrm{CX}$.

Our observations of case.com reveal that customers, even those who are experienced online shoppers, looking for support, assurance that what they are ordering and are going to receive is confirmation of their good/excellent choices. Yet, from case.com's point of view, customer calls about the company's online processes are needless. In spite of the fact that the company's online experience is extremely well designed and operates excellently, buyers are disappointed when redirected to the website because such undermines the confidence and assurance they seek. There is no attempt on the company's part to truly understand the reasons a customer orders or returns a particular product, or what needs to be done to rectify the issues causing consumer frustration. Consumers' questions are not acknowledged, leading to dissatisfaction with case.com.

These findings surprised case.com because the company had never realized that buyers order goods to give away or use later. The assumption was that upon receipt of an order, a customer immediately opens, inspects and tries the product. Despite an attempt to improve order fulfilment by adding an online question, "Why do you need this particular product now?", this tactic did not yield the intended improvement. Customers kept calling case.com to assure themselves of making the proper selection for products and to confirm delivery as already indicated online. However, the strategy to train contact centre employees to show more empathy and act responsively led to higher customer satisfaction ratings, evident in NPS scores from 2016 on (see Figure 2)

In conclusion, we observed that case.com's focus on creating a highly effective and satisfactory digital process did not yield meaningful TCX. It seems that company has overlooked the effect on TCX of other channels such as telephone use, physical distribution systems and outsourced suppliers.

\subsection{Coolblue}

Coolblue is a Dutch e-commerce company that was founded in 1999 by CEO, Pieter Zwart, Paul de Jong and Bart Kuijpers (for a history in Dutch, see https://www.coolblue.nl/geschiedenis). The company operates over 300 individual webshops and 8 physical stores under the Coolblue brand. In 2016, Coolblue reported sales of $€ 857$ million, a $55 \%$ increase compared to the previous year [53].

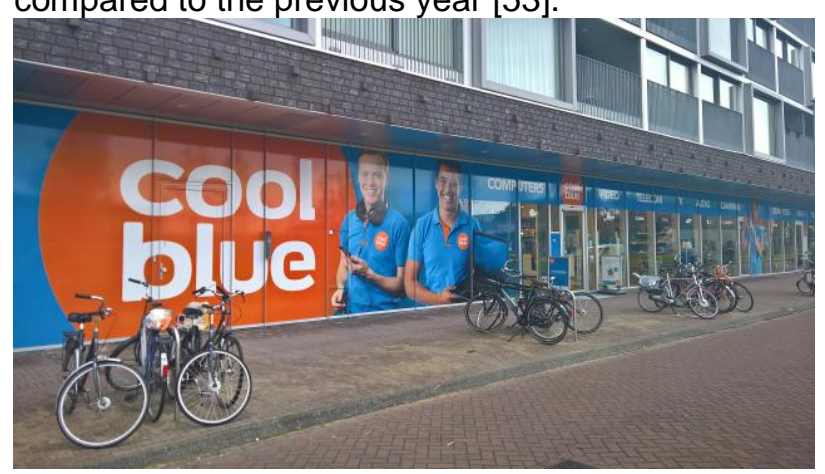

Figure 3. A Coolblue store in Groningen

Coolblue is mainly a consumer electronics provider. It trademarks separate webshops for each of its product groups, with URL domain extensions .nl and .be variants for each one, supporting the company's use of a niche strategy. In 2016, Coolblue had 319 specialized webshops in the Benelux, as well as nine physical stores. Coolblue is active in the Netherlands and Belgium. The company started with webshops such as MP3man.nl, PDAshop.nl and Laptopshop.nl. In the Netherlands (Rotterdam, Eindhoven, Groningen, Amsterdam, Utrecht and The Hague), Coolblue has dozens of webshops and six physical stores (see Figure 3). In Belgium (Antwerp, Zaventem and Lochristi), the company owns and operates three physical retail locations. The main office is in Rotterdam. Coolblue has a distribution centre in Capelle aan den ljssel. In 2013, the firm opened a facility $\left(13,000 \mathrm{~m}^{2}\right)$ in Tilburg in 2013, and another, another larger distribution centre $(22,000$ $\mathrm{m}^{2}$ ) was added there in 2015. An additional six halls were added in 2016 and 2017. In total, the distribution 
operation in Tilburg is 88,000 sq.m. excluding three atypical offices. In 2012 and 2013, Coolblue was voted the best webshop in the Netherlands in the consumer electronics category during the Thuiswinkel Awards, a yearly event that recognises online-operating retailers in the Netherlands.

The company's online process is lean and simple. One can order following these steps: selection of product, placement in a digital shopping basket, choosing between delivery or pick up, ordering via a Coolblue account, checking the order and paying. Aside from the online system, Coolblue uses several other channels to interact with its customers, not only during all transaction and contact stages, but also throughout use and other events occurring in consumers lives.

For fulfilment, Coolblue has its own delivery service. In order to delight the customer during delivery, Coolblue applies the customer journey approach to achieve this goal with special attention focused on the last kilometres of delivery. To ensure order receipt is a moment-of-truth for Coolblue customers, the company promises: "We will come, no matter what." Consider the example of a customer's washing machine order: An hour from arrival, the delivery van can be followed realtime via an online link sent to the customer in advance. Thirty minutes before delivery, the courier phones the customer receiving the order to report the exact arrival time, simultaneously introducing himself so the customer knows whom to expect. If the customer is not already waiting at the door when the delivery person arrives, he knocks or rings the doorbell. The courier surprises the customer with the new washing machine packaged as a present as it is being removed from the truck, carried to the space intended for its use, and installed by Coolblue staff. The installation team provide the customer with spoken and written use and maintenance instructions about the new machine. Upon departure, they take the old device.

Delivered in a box, Coolblue products are configured to look like a relevant and appropriate present and decorated with friendly and funny communications (Figure 4). Should the recipient not be home when the package is delivered, the staff leaves a funny card telling the customer what can be done to receive the product at a more convenient time. Customers can choose to pick up the order in a physical store, have it redelivered at a more convenient time, or delivered at another address.

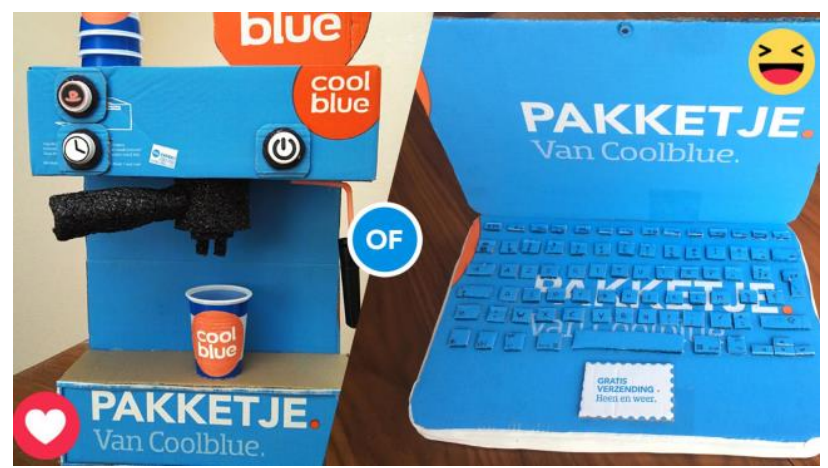

Figure 4. Two examples of how Coolblue makes package reception and unpacking an experience
How does Coolblue's physical delivery process affect the TCX? Coolblue seems to respond to all questions and concerns during the non-digital customer journey, such as: "Will the delivery be on time?" "I don't like strangers in my house." "Is installation included?" "How do I dispose of the old device or machine?" In addition, the company's delivery is fast and pleasant.

However, Coolblue does not ignore the digital experience at all. At the start of the company, the founders have written two goals on a wall in the main office: 'to strive for the highest possible customer satisfaction and profit contribution'. To this day, these two objectives apply to every department, including the customer service, brand and online marketing department. Together they go for the optimal result for Coolblue. These goals are equally important and affect the entire business. This includes social media.

For example, Coolblue has no social media command centre like most companies. Social media use is a joint responsibility of all employees, so posts come from departments across the entire organization. The company's social media marketer (SMM) acts in an advisory role: depending on the target group one wants to reach, the SMM staff member recommends the appropriate network or platform for posts, e.g., Twitter, Linkedln, Facebook, YouTube, etc.. Next, the SSM determines the objective, budget and appropriate social network(s) best for reaching target consumers. All in all, Coolblue's social media approach is service driven. It is squarely focused on regular, consistent communication of the company's brand promise, "We will do anything for a smile".

The customer service unit has a dedicated team that handles questions via social media. The rule is that all customer requests placed within the customer service opening hours will be answered within 30 minutes. The platforms used for consumer interaction are those noted earlier, Facebook, Twitter, Linkedln, and YouTube. The same service level applies to all social media networks. Questions are answered in order of arrival; and no use is made of influencer scoring.

Customer requests are handled by a team of customer service representatives organized according to specializations. For calls about sports watches, a member of the staff knowledgeable about these products handles on the subject. For questions about a new laptop, the customer is served by someone who is knowledgeable about the latest devices. Every customer is of equal importance to Coolblue. Again, the aim is to do "anything for a smile".

IT developers are also involved in online social interactions with customers. For example, via Twitter a customer requested Coolblue to implement a new PayPal option. The company did so, and the developer who established this new option contacted the customer after it was introduced and asked, "Can you announce the PayPal option to others via Twitter?"

As it does with its distribution centres, delivery service, social media, customer service and online interaction systems, Coolblue invests heavily in physical stores. Many customers like to feel, touch and hold a product for a moment and get face-to-face advice about which 
item is best for them, especially when their purchases involve more expensive products. In the cities where Coolblue addresses this customer need by opening physical stores, the company experienced strong increases in online sales and customer satisfaction.

In what could be described as obsessive, Coolblue monitors and measures customer satisfaction and many other processes using different metrics. The NPS [54] is central to this and is calculated on the basis of the question, "Would you recommend Coolblue to someone else?" The quality of the customer service staff is also measured. If there has been contact with an employee, Coolblue will ask the customer if he would theoretically employ the person in question. Also, customer service representatives are given the time to interact with customers by sending five handwritten postcards to those they have had contact with that day. For example, a card can be sent to wish a customer success in writing his thesis on his newly acquired laptop. Coolblue involves its suppliers in contributing to achieving higher customer satisfaction. The company measures NPS per channel and per product supplier. And once a year, there is a supplier's 'happy hour' in which the NPS of the various suppliers are presented per product category.

Continuous improvement is embedded in all business processes, as Coolblue does not settle for the status quo. "Every day a little better" is written on the walls as a motto; and putting the customer first is also used by the company as an employee goal.

Coolblue knows how to serve the customer through its offline and digital channels. The company deserves accolades for its success in effectively connecting strategy to business objectives across the entire organization by building, nurturing and achieving relationships with its customers. Customers who purchase products from Coolblue get the feeling (because of the extreme retargeting) that they are included in a customer group with a certain profile entailing an experience that goes beyond touchpoint levels. Through its culture, Coolblue has positioned itself firmly for longstanding success through repeated and better discovery of the needs of its customers on a consistent basis. As a result, Coolblue could make the 'flat' remarketing campaigns that are still widely used now part of the past. Customers want to be treated as individuals and not as a group. All the data and intelligence that Coolblue collects daily is the right prelude.

\section{DISCUSSION AND CONCLUSION}

\subsection{Reflecting on the two cases}

Comparing the two cases to one another we can observe similarities, but also quite a few differences. Coolblue has a clear strategy aimed at obtaining a meaningful TCX. Case.com's strategy is directed toward creating an easy, simple and hassle-free digital experience, while not paying attention to other, more physical experiences like personal assistance and response, interacting in other channels than just the digital one, and such. The latter's 'myopic' approach was an important factor affecting the decline in overall customer satisfaction and loyalty, manifested in increasing product returns.

Whereas Coolblue considers the entire customer journey, including delivery, installation and even disposal of a product giving the customer a feeling of control throughout the complete journey, case.com focuses on improving and optimizing the online process, initially even taking control of the buying process out of customers' hands, resulting in confused buyers looking for confirmation and assurance that they made the right choice.

Buying at Coolblue does not mean that the product you purchased will operate or function perfectly. In that respect, both companies in our case studies depend on the quality of the goods produced by their manufacturers. However, Coolblue is aware that not all their customers are knowledgeable to distinguish flaws and possible malfunctions on sight, especially in online environments. The company assists, directs and supports customers in their product selections in a personal way, in order to prevent them from taking wrong steps and making bad decisions.

Where both Coolblue and case.com make use of third parties offering the two companies' products on those parties' platforms or delivering them to customers, case.com makes no attempts to control these providers in order to offer good customer experiences. The company seemed to be only interested in creating a smooth and meaningful digital experience, and therefore measuring only satisfaction for this online process. Coolblue, on the other hand, seems to be aware of their third party responsibility, collaborating with, facilitating and even supporting these suppliers and service organizations in creating consistent and seamless experiences. By ensuring it obtains customer feedback in all available channels, linking distinct measurements to the customer journey, Coolblue delivers moments of truth and applies the peak-end-rule to every single customer.

Finally, we observe that Coolblue has created a company culture with the aim and intention of customercentricity and customer transformation. Although we cannot label case.com as not being customer-centric, its culture appears to condone indifference among management and employees in view of the company's high turnover. Creating awareness and providing training for all staff is gradually altering this stance in favour of customer.

\subsection{Final considerations}

Today, customers are interacting with companies through a plethora of channels and touchpoints. CX and customer behaviour in this evolving marketplace are viewed as one of the most important research challenges in general and for companies. Some firms may choose to focus on a single-channel strategy, i.e. the digital channel, to accomplish a memorable TCX, in spite of research demonstrating that an omnichannel strategy integrating all aspects of the supply chain and all activities in the different channels can result in outstanding $\mathrm{CX}$, both within and across channels [47]. 
An important feature of mass customization (MC) enterprises is that their product uniqueness is important in shaping $C X$ [55] and is resulting in growing interest from such companies for $\mathrm{CX}$ [56]. On the other hand, many MC companies' interactions with consumers rely largely online, so the danger of focusing solely on the digital channel is then tempting. We have argued, however, that concentration only on digital $C X$ constitutes a myopic view. Several studies [32, 52] have demonstrated that indirect use of digital apps and human interaction combined are of more importance for TCX than solely digital interaction. Our study demonstrated that case.com's singular focus on digital experience can lead to counterproductive results such as lower customer satisfaction and decreased loyalty. However, in the case of Coolblue, the CX in non-digital stages of an offering or service play an important, if not vital, role in the holistic service experience. Compared with online or digital experiences, these non-digital experiences do not require the actual use of online apps or direct contact with the user [52].

Managers are encouraged not to restrict $C X$ to direct digital use only. Indirect and non-digital $\mathrm{CX}$ enable managers to gain deep insights into the everyday TCX of current and potential customers. Therefore, to optimize the whole CX, companies should pursue the omnichannel approach, focusing on both digital and physical channels while envisioning the customer journey.

\subsection{Limitations and future research}

The present study is based both on conceptual reasoning and practice. The two cases considered provide empirical evidence that support our conceptual premise. For instance, one can wonder about $\mathrm{MC}$ companies that have successfully deployed a MC strategy have such total control of the supply chain that they show no interest for the $\mathrm{CX}$ and, as a result, actually experience loyalty issues, as was the case with case.com. One can also wonder whether different approaches are needed for the different types of experiential appeals [17] as discussed in section 2.1. Unfortunately, the evidence provided by the two cases analysed in the present article do not provide enough information to say something about these conjectures. Additional observations are needed, not only to address these conjectures, but also to increase the generalizability of the results. Consequently, wider empirical research that considers other types of products and services, different types of customers, as well as companies of different sizes, is a desirable way to continue the direction of the present research. Another possibility to extend this line of enquiry is to conduct additional case studies in order to develop a conceptual model that considers the relevant factors, causes and constructs which influence TCX and, subsequently, validate this conceptual model.

\section{REFERENCES}

[1] Journée, R.J.A. and Weber, M.E.A. (2014), "A Bonded Experience: "Value Creation as the Creation of an Experience, Within a Business Relationship"," in Proceedings of the 7th World Conference on Mass Customization, Personalization, and Co-Creation (MCPC 2014), Aalborg, Denmark, February 4th 7th, 2014, Brunoe, T.D., Nielsen, K., Joergensen, K.A., and Taps, S.B., Eds., ed: Springer International Publishing, pp. 1-16.

[2] Mascarenhas, O.A., Kesavan, R. and Bernacchi, M. (2006), "Lasting customer loyalty: a total customer experience approach", Journal of Consumer Marketing, vol. 23, pp. 397-405.

[3] Sandrin, E. (2017), "Synergic Effects of Sales-Configurator Capabilities on Consumer- Perceived Benefits of MassCustomized Product", International Journal of Industrial Engineering and Management, Vol. 8, No. 3, pp. 177-188.

[4] Schnurr, B. and Scholl-Grissemann, U. (2015), "Beauty or function? How different mass customization toolkits affect customers' process enjoyment", Journal of Consumer Behaviour, Vol. 14, No. 5, pp. 335-343.

[5] Kaur, P., Dhir, A., Chen, S. and Rajala, R. (2016), "Understanding online regret experience using the theoretical lens of flow experience", Computers in Human Behavior, Vol. 57, pp. 230-239.

[6] Trentin, A., Perin, E. and Forza, C. (2014), "Increasing the consumer-perceived benefits of a mass-customization experience through sales-configurator capabilities", Computers in Industry, Vol. 65, No. 4, pp. 693-705.

[7] Barman, S. (2013), An Overview of Mass Customization in Practice. University of Oklahoma. Norman, OK..

[8] Janos, S., Monika, T., Jozef, Z. and Jozsef, S. (2018), "Mass customization model in food industry using industry 4.0 standard with fuzzy-based multi-criteria decision making methodology", Advances in Mechanical Engineering, Vol. 10, No. 3, p. 1687814018766776

[9] Thompson, C.J., Locander, W.B. and Pollio, H.R. (1989), "Putting Consumer Experience Back into Consumer Research: The Philosophy and Method of Existential-Phenomenology", The Journal of Consumer Research, Vol. 16, No. 2, pp. 133-146.

[10] Thompson, C.J., Locander, W.B. and Pollio, H.R. (1990), "The Lived Meaning of Free Choice: An Existential-Phenomenological Description of Everyday Consumer Experiences of Contemporary Married Women", The Journal of Consumer Research, Vol. 17, No. 3, pp. 346-361.

[11] Schmitt, B. (1999), "Experiential Marketing", Journal of Marketing Management, Vol. 15, No. 1-3, pp. 53-67.

[12] Holbrook, M.B. and Hirschman, E.C. (1982), "The Experiential Aspects of Consumption: Consumer Fantasies, Feelings, and Fun", Journal of Consumer Research, Vol. 9, No. 2, pp. 132-140.

[13] Schmitt, B. (2009), "Editorial. The concept of brand experience", Journal of Brand Management, Vol. 16, pp. 417-419.

[14] Pine, B.J. and Gilmore, J.H. (1999), The Experience Economy: Work Is Theatre \& Every Business a Stage. Boston, Mass.: Harvard Business School Press.

[15] Addis, M. and Holbrook, M.B. (2001), "On the conceptual link between mass customisation and experiential consumption: an explosion of subjectivity", Journal of Consumer Behaviour, Vol. 1, No. 1, pp. 50-66.

[16] Carú, A. and Cova, B. (2003), "Revisiting Consumption Experience: A More Humble but Complete View of the Concept", Marketing Theory, Vol. 3, No. 2, pp. 267-286.

[17] Zarantonello, L. and Schmitt, B. (2010), "Using the brand experience scale to profile consumers and predict consumer behavior", Journal of Brand Management, Vol. 17, No. 7, pp. 532-540.

[18] Verhoef, P.C., Lemon, K.N., Parasuraman, A., Roggeveen, A., Tsiros, M. and Schlesinger, L.A. (2009), "Customer Experience Creation: Determinants, Dynamics and Management Strategies", Journal of Retailing, Vol. 85, No. 1, pp. 31-41.

[19] Barnes, J.G. and Wright, J.W. (2012), "A Framework for Applying Customer Insight and Context to the Development of a Shopping Experience Strategy", in Service Management, Kandampully, J., Ed., ed New York: Springer, pp. 43-65.

[20] Grewal, D., Levy, M. and Kumar, V. (2009), "Customer Experience Management in Retailing: An Organizing Framework", Journal of Retailing, Vol. 85, No. 1, pp. 1-14.

[21] Sorescu, A., Frambach, R.T., Singh, J., Rangaswamy, A. and Bridges, C. (2011), "Innovations in Retail Business Models", Journal of Retailing, Vol. 87, Supplement 1, pp. S3-S16. 
[22] Gentile, C., Spiller, N. and Noci, G. (2007), "How to Sustain the Customer Experience: An Overview of Experience Components that Co-create Value With the Customer", European Management Journal, Vol. 25, No. 5, pp. 395-410.

[23] Shaw, C. and Ivens, J. (2005), Building Great Customer Experiences, Revised ed. New York: Palgrave MacMillan.

[24] Berry, L.L., Carbone, L.P. and Haeckel, S.H. (2002), "Managing the Total Customer Experience", MIT Sloan Management Review, Vol. 43, No. 1, pp. 1-5.

[25] Ponsonby-Mccabe, S. and Boyle, E. (2006), "Understanding brands as experiential spaces: axiological implications for marketing strategists", Journal of Strategic Marketing, Vol. 14 No. 2, pp. 175-189.

[26] Prahalad, C.K. and Ramaswamy, V. (2004), "Co-creation experiences: The next practice in value creation", Journal of Interactive Marketing, Vol. 18, No. 3, pp. 5-14.

[27] Morrison, S. and Crane, F.G. (2007), "Building the service brand by creating and managing an emotional brand experience", Journal of Brand Management, Vol. 14, No. 5, pp. 410-421.

[28] Berry, L.L. and Carbone, L.P. (2007), "Build Loyalty Through Experience Management", Quality Progress, Vol. 40, No. 9, pp. 26-32.

[29] Boswijk, A., Thijssen, T. and Peelen, E. (2005). A new perspective on the Experience Economy. Meaningful Experiences. The European Centre for the Experience Economy, The Netherlands.

[30] Ramaswamy, V. and Gouillart, F.J. (2010), The Power of CoCreation. Build It With Them To Boost Growth, Productivity, and Profits, New York: Free Press.

[31] Zomerdijk, L.G. and Voss, C.A. (2011), "NSD Processes and Practices in Experiential Services", Journal of Product Innovation Management, Vol. 28, No. 1, pp. 63-80.

[32] Aichner, T. and Gruber, B. (2017), "Managing Customer Touchpoints and Customer Satisfaction in B2B Mass Customization: A Case Study", International Journal of Industrial Engineering and Management, Vol. 8, No. 3, pp. 131-140.

[33] Normann, R. (2007), Service Management: Strategy and Leadership in Service Business, 3rd ed. Chichester: John Wiley \& Sons Ltd.

[34] Cockburn, A., Quinn, P. and Gutwin, C. (2017), "The effects of interaction sequencing on user experience and preference," International Journal of Human-Computer Studies, Vol. 108, pp. 89-104.

[35] Do, A.M., Rupert, A.V. and Wolford, G. (2008), "Evaluations of pleasurable experiences: The peak-end rule", Psychonomic Bulletin \& Review, Vol. 15, No. 1, pp. 96-98.

[36] Schurr, A., Rodensky, D. and Erev, I. (2014), "The effect of unpleasant experiences on evaluation and behavior", Journal of Economic Behavior \& Organization, Vol. 106, pp. 1-9.

[37] Ariely, D. (2009), Predictably Irrational. The Hidden Forces that Shape Our Decisions, Revised ed. London: HarperCollins Publishers.

[38] Altounian, D., Wiley, R., Woo, V. and Roberts, S. (2016), "From Customer Engagement to the Customer Journey: Understanding the Drivers of Engagement in B2C and B2B Environments", in Let's Get Engaged! Crossing the Threshold of Marketing's Engagement Era, Obal, M.W., Krey, N. and Bushardt, C., Eds., ed: Springer International Publishing, pp. 611-614.

[39] Anderl, E., Becker, I., von Wangenheim, F. and Schumann, J.H. (2016), "Mapping the customer journey: Lessons learned from graph-based online attribution modeling", International Journal of Research in Marketing, Vol. 33, No. 3, pp. 457-474.

[40] Chatzopoulos, C.G. and Weber, M. (2018), "Challenges of Total Customer Experience (TCX): Measurements beyond Touchpoints", International Journal of Industrial Engineering and Management, Vol. 9, No. 4, pp. 187-196.

[41] Wolny, J. and Charoensuksai, N. (2016), "Multichannel Customer Journeys: Mapping the Effects of Zmot, Showrooming and Webrooming", in Marketing Challenges in a Turbulent Business Environment, Groza, M.D. and Ragland, C.B., Eds., ed: Springer International Publishing, pp. 205-206.

[42] Leinonen, M. (2018), "Customer experience through the customer journey in a multichannel environment : case Veikkaus", MSc Master Thesis, LUT School of Business and Management, Lappeenranta University of Technology,

[43] Wallace, D.W., Giese, J.L. and Johnson, J.L. (2004), "Customer retailer loyalty in the context of multiple channel strategies", Journal of Retailing, Vol. 80, No. 4, pp. 249-263.
[44] Klaus, P. and Nguyen, B. (2013), "Exploring the role of the online customer experience in firms' multi-channel strategy: an empirical analysis of the retail banking services sector", Journal of Strategic Marketing, Vol. 21, No. 5, pp. 429-442.

[45] Frow, P. and Payne, A. (2007), "Towards the 'perfect' customer experience", Journal of Brand Management, Vol. 15, No. 2, pp. 89-101.

[46] Deshpande, D., Khanna, K., Singh, N. and Roshan, R. (2011), "Emerging Multichannel Customer Experiences in Grocery Retail", WIPRO Technologies, Bangalore, India

[47] Sousa, R. and Voss, C.A. (2006), "Service Quality in Multichannel Services Employing Virtual Channels", Journal of Service Research, Vol. 8, No. 4, pp. 356-371.

[48] Hwang, J. and Seo, S. (2016), "A critical review of research on customer experience management: theoretical, methodological, and cultural perspectives", International Journal of Contemporary Hospitality Management, Vol. 28, No. 10, pp. 2218-2246.

[49] Gilmore, J. and Pine II, B.J., Eds. (2000), Markets of One: Creating Customer-Unique Value through Mass Customization. Boston MA: Harvard Business School Publishing.

[50] Pine II, B.J. and Gilmore, J.H. (2014), "A leader's guide to innovation in the experience economy", Strategy \& Leadership, Vol. 42, No. 1, pp. 24-29.

[51] Pine II, B.J. and Korn, K.C. (2011), Infinite Possibility: Creating Customer Value on the Digital Frontier. San Francisco, CA: Berrett-Koehler.

[52] Dube, A. and Helkkula, A. (2015), "Service experiences beyond the direct use: indirect customer use experiences of smartphone apps", Journal of Service Management, Vol. 26, pp. 224-248.

[53] DutchNews. (2017, 2018-5-25). Web shop Coolblue sees sales rise $55 \%$, to take on 1,500 new staff. (March 1, 2017). Available at https://www.dutchnews.nl/news/2017/03/web-shop-coolbluesees-sales-rise-55-to-take-on-1500-new-staff/

[54] Reichheld, F. (2006), The Ultimate Question. Driving Good Profits and True Growth. Boston, MA: Harvard Business School Press.

[55] Franke, N. and Schreier, M. (2008), "Product uniqueness as a driver of customer utility in mass customization", Marketing Letters, Vol. 19, No. 2, pp. 93-107.

[56] Jain, S., Sundström, M. and Peterson, J. (2018), "Mass Customized Fashion: Importance of Data Sharing in the Supply Chain", in Nordic Retail and Wholesale Conference, Reykjavík, 7-8 November, 2018, Iceland. 